\title{
Commentary: Steps toward understanding the root of the issue
}

Andrew Mesher, MD, ${ }^{\mathrm{a}}$ Muhammad Aftab, MD, ${ }^{\mathrm{a}}$ Thomas G. Gleason, MD, ${ }^{\mathrm{b}}$ and T. Brett Reece, $\mathrm{MD}^{\mathrm{a}}$
The article in this issue of the Journal by De Paulis and colleagues ${ }^{1}$ summarizes 2 decades of experience with the Valsalva graft from the unique perspective of the innovators who developed the device. Since the initial descriptions of the valve-sparing operations by David and Feindel $^{2}$ and Yacoub and colleagues, ${ }^{3}$ numerous modifications in technique, some iterative and others progressive, have been proposed to optimize various aspects of the repair. The Valsalva graft represents a device adjunct to surgical technique in the evolution of root procedures to address the potential advantages of neosinus creation. The incorporation of a bulged skirt portion between 2 cylindrical sections of graft creates a construct around which neosinuses and a trilobate conformation of the aortic root may be more reliably recreated. Finite element models ${ }^{4}$ demonstrating improved valve opening and closure while minimizing leaflet stress have provided experimental rigor beyond intuitive sense to "mimic Mother Nature" in recapitulating a configuration similar to that of the native root.

Indeed, use of the Valsalva graft has gained favor among may aortic surgeons in both valve-sparing root operations and the Bentall procedure. Despite improved geometric mimicry of the native root and favorable experimental data supporting mitigated leaflet stress and mobility, however, clinical superiority versus a cylindrical graft or modified cylindrical graft remains unproven. In experienced centers, midterm and long-term outcomes with both types of grafts for valve-sparing root operations are excellent. ${ }^{5,6}$

De Paulis and colleagues ${ }^{1}$ acknowledge the paramount importance of additional technical factors in valve-sparing root procedures to the long-term durability of repair and freedom from aortic insufficiency beyond the single factor of graft type. In fact, one may argue that valve placement

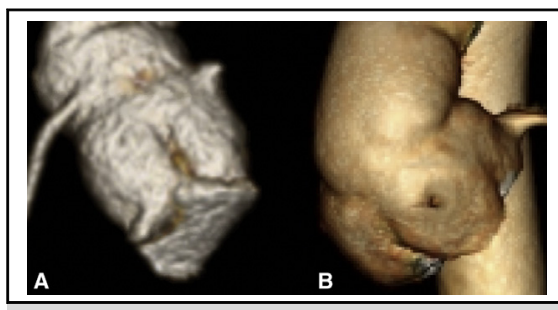

The Valsalva graft (A) development inspired techniques for sinus creation in tube grafts $(B)$, too.

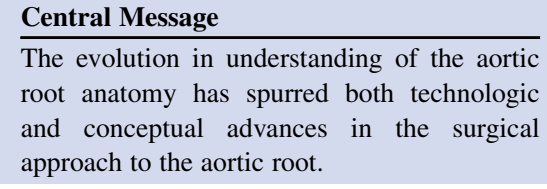

See Article page 1758 . within the Valsalva graft, given that the bulged portion is essentially a spherical shape before commissural reattachment at the neosinuotubular junction, incorporates an additional degree of freedom necessitating more precision than a cylindrical graft. Graft oversizing, 2-graft technique, plication of the intercommissural spaces,, 5 and other strategies to create a similar recess outside the leaflets with a cylindrical graft may confer the same clinical advantages. The complexity of successful neosinus creation is mitigated by experience and seems to be largely unaffected by the choice of graft type.

De Paulis and colleagues ${ }^{1}$ deserve congratulations for their achievements in the development of the Valsalva graft and resultant contributions to the advancement of aortic surgery. The question of whether a bulged graft for root replacement improves patient outcomes remains unanswered; however, innovations like the Valsalva graft continue to drive knowledge and understanding of the complexity of the mechanicals of the aortic root.

\section{References}

1. De Paulis R, Scaffa R, Weltert L, Salica A. Mimicking Mother Nature: the Valsalva graft. J Thorac Cardiovasc Surg. 2020;159:1758-63.

2. David TE, Feindel CM. An aortic valve-sparing operation for patients with aortic incompetence and aneurysm of the ascending aorta. J Thorac Cardiovasc Surg. 1992;103:617-21; discussion 622.

3. Yacoub MH, Gehle P, Chandrasekaran V, Birks EJ, Child A, RadleySmith R. Late results of a valve-preserving operation in patients with aneurysms of the ascending aorta and root. J Thorac Cardiovasc Surg. 1998;115: 1080-90. 
4. Grande-Allen KJ, Cochran RP, Reinhall PG, Kunzelman KS. Re-creation of sinuses is important for sparing the aortic valve: a finite element study. $J$ Thorac Cardiovasc Surg. 2000;119:753-63.

5. David TE, Feindel CM, David CM, Manlhiot C. A quarter of a century of experience with aortic valve-sparing operations. J Thorac Cardiovasc Surg. 2014;148:872-80.
6. De Paulis R, Chirichilli I, Scaffa R, Weltert L, Maselli D, Salica A, et al. Longterm results of the valve reimplantation technique using a graft with sinuses. $J$ Thorac Cardiovasc Surg. 2016;151:112-9.

7. Sundt TM. Valve-sparing root reconstruction. Oper Tech Thorac Cardiovasc Surg. 2005; 10:272-85. 